\title{
What are the New Challenges in Civil Engineering?
}

\author{
Hossein Nowamooz* \\ ICUBE Laboratory, INSA de Strasbourg, France
}

*Corresponding author: Hossein Nowamooz, Associate professor, ICUBE Laboratory, INSA de Strasbourg, Strasbourg, France.

Received Date: October 01, 2018

Published Date: October 09, 2018

\section{Introduction}

Civil engineering is faced to new challenges in the coming years due to the technological developments, the increasing population and the environmental restrictions. Proposing a more sustainable and proper material instead of the classical existing materials is one of biggest challenges in future. To reduce the costs, the local material may play an important role in the constructions, as well. The new proposed material should respect also the environmental challenges. These new materials need also new standards, classification methods, calculating methods or even new construction methods. Furthermore, the newly developed technologies such as Building Information Modeling (BIM), 3D printing, drone equipment or network connectivity will be helpful to accelerate the changes. This access to the reality is easier and we may lose less time to experience the difficulties and to find the proper solutions.

These modifications change our conventional theoretical approaches, as well. The new materials should be environmentally, mechanically and locally acceptable. This demands a better interaction of different fields to propose a suitable theoretical approach, effectively functional for the concerned designers or operators.

Another major challenge will be the environmental concerns due to earth global warming and its climate changes. The problem becomes more and more factual. This also modifies highly the construction strategies since it influences first the construction materials and then their structure. We are facing a very soft revolution in civil engineering. A future civil engineer will have some new challenges to characterize newly developed construction materials, to apply new construction methods and to get use to proper calculating approaches. This needs time but I think that the era has just started.

\section{Acknowledgment}

I am really grateful for this opportunity to do a general editorial opinion for the first issue.

\section{Conflict of Interest}

No conflict of interest. 